\title{
Skin Cancer Treatment by Nanoskin Cellulose: Future Cancer Wound Healing
}

\author{
Pierre Basmaji ${ }^{1}$, Gabriel Molina de Olyveira ${ }^{2}$, Mohamed M. Kanjou ${ }^{3}$ \\ ${ }^{1}$ Innovatec's-Biotechnology Research and Development, São Carlos, Brazil \\ ${ }^{2}$ Biomedical Engineering Department, UFABC University, São Bernardo do Campo, Brazil \\ ${ }^{3}$ SKGH Ajm., GEM International, Dubai, United Arab Emirates \\ Email: gabriel.ufabc@gmail.com
}

How to cite this paper: Basmaji, P., de Olyveira, G.M. and Kanjou, M.M. (2021) Skin Cancer Treatment by Nanoskin Cellulose: Future Cancer Wound Healing. Journal of Biomaterials and Nanobiotechnology, 12, 1-6.

https://doi.org/10.4236/jbnb.2021.121001

Received: October 30, 2020

Accepted: December 11, 2020

Published: December 14, 2020

Copyright (c) 2021 by author(s) and Scientific Research Publishing Inc. This work is licensed under the Creative Commons Attribution International License (CC BY 4.0).

http://creativecommons.org/licenses/by/4.0/

\begin{abstract}
Cancer cells can be proliferating in a few months and years. It depends on cancer stage. Chemotherapy, immunotherapy and anti-metabolic drugs have been used in order to kill cancer cells and prevent immune system weakly and metastasis. However, such drugs can damage healthy cells too. Natural ways to cancer treatments may help whole body to cancer cells. In this work, it was taking off cancer nodule to skin cancer by surgery and we treat the nodule as wound, using Nanoskin ${ }^{\circledR}$ advance cell therapy (ACT), natural extra cellular matrix which releases nutrients to the skin cancer. Our result shows that the cancer nodule disappears in few weeks in skin, because of natural membrane treatment. In addition, we obtained complete wound healing due anticancer nutrients (beta-glucan) delivery to skin.
\end{abstract}

\section{Keywords}

Nanoskin Cellulose, Bacterial Cellulose, Wound Healing, Skin Cancer, In Vivo Analysis

\section{Introduction}

Cancer arises from a cellular anomaly in the human body leading to death of patient. All normal cells go through the same phases until reach cell division. The basic difference is the fact that in normal cells, there is a balance between born and death cells and cancer cells not [1] [2]. There are mainly two major classes of cancer genes: proto-oncogenesis and tumor suppressor genes. Proto-oncogeneses increase cell division while tumor suppressors decrease [3].

More than 25 years ago, it was discovered mutations in Ras proto-oncogenes in the DNA of human tumors. Mainly, there are changes in the receptors of 
cancer cells that ultimately lead to mutant cancerous proteins, which expend dedication by researchers in the fight in gene therapy against cancer [4] [5].

Among the nanotechnology strategies for the cancer treatment, there are several paths: nanoencapsulation of anticancer drugs, target delivery of antineoplastic therapy, combination of nanoparticles with radiotherapy and combination with physical modalities of cancer therapy [6] [7].

Several kinds of nanoparticles are used in the cancer treatment, especially polymer and magnetic, the first for diagnosis, imaging and controlled release and the second for controlled release and the formation of the recent multifunctional nanoparticles [8] [9].

Still, natural membranes can be used in cancer treatment too, mainly in tumoral wounds or ulcerating wounds happening due to loss of skin integrity, resulting from uncontrolled cellular proliferation and future skin cancer [10]. The ideal skin substitute using natural membrane will give replacement of dermis and epidermis, lost by skin cancer.

Nanoskin ${ }^{\circledR}$ ACT natural extra cellular matrix bacterial cellulose (ECM-BC) releases nutrients from bacterial cellulose fermentation to the skin tissue. Produced nanofibers of fermentation has high concentration of secondary metabolic such as diterpene and alkaloids', that improve skin nutrients and improve immune system too [11].

Besides, Nanoskin ${ }^{\circledR}$ natural membranes have $\beta$-glucan polysaccharide, which is effective anticancer agent and immunogenic substance. When it is linked in cellular receptors, it increases immune body response. Such natural membranes change ECM synthesis of new vessels, granulation tissue and epithelialization that are produced in patient skin [12] [13] [14] [15] [16].

Several articles were published by our researches since 2015, using Nanoskin membranes for different wound healing treatments, such as in diabetic ulcers, venous ulcers, skin cancer, amputation and different accidents [17] [18] [19] [20].

In this work, it shows recent wound healing in skin cancer. In order to produce natural membranes with drug delivery and immunogenic, bacterial cellulose fermentation was changed with chondroitin sulfate, hyaluronic acid and beta glucan.

\section{Materials and Methods}

\subsection{Materials}

The bacterial cellulose raw material was provided from Innovatećs (São Carlos SP, Brazil). Chondroitin sulfate, hyaluronic acid and beta glucan were purchased from Sigma Aldrich.

\subsection{Methods}

1) Synthesis of Bacterial Cellulose and bacterial cellulose/chondroitin sulfate/hyaluronic acid and beta glucan

Bacterial cellulose (BC) was produced by fermentation change of Gram-negative 
bacteria Gluconacetobacter xylinus, which will obtain from culture medium in the pure 3-D structure, consisting of an ultra fine network of cellulose nanofibers [21] [22]. The acetic fermentation process was achieved by using glucose as a carbohydrate source. Results of this process were acetic acid and a nanobiocellulose biomass. The modifying process was based on the addition of hyaluronic acid, chondroitin sulfate and beta glucan $(1 \% \mathrm{w} / \mathrm{w})$ to the culture medium before bacteria inoculation and after bacterial cellulose hydrogel is dried in a oven to produce bacterial cellulose mats (Figure 1).

\subsection{Characterization}

In vivo analysis-It was made clinical study under supervision of Dr. Pierre Basmaji with follow evaluation model: Two young people with Skin cancer received Nanoskin natural membranes and presents different time treatments. The 2 patients have basal carcinoma. The skin cancer was treated by microneedling to improve textural issues on the skin, in fact microneedling an actually improve scar from skin cancer. After microneedling, Nanoskin ACT has been applied to wound, the skin epithelization and cauterization mean the skin are restored. However, if the cancer is still present the wound cannot be cicatrized or can open later. Our patients, until this date don't present any skin wound anomalies.

\section{Results and Discussion}

\section{In Vivo Analysis}

Patient (P.M) entered in Nanoskin Clinical on 07/31/2020 under supervision of Dr. Pierre Basmaji, diagnosed with skin cancer. Wound was infected and cancer cells are accumulated all over the wound. Classic dressing was used (Natural Nanoskin ${ }^{\circledR}$ ACT) with antiseptic agents in 07/31/2020. In August 2020 (1 week), after using the Bacterial cellulose material in all days, it can be observed an excellent new tissue in old skin cancer area of the wound and reduced wound area, the same behavior of our article published in 2020 [20] (Figure 2).

Another Patient (R.R) entered in Nanoskin Clinical on 06/04/2020 under supervision of Dr. Pierre Basmaji, diagnosed with skin cancer. Wound was infected and cancer cells are accumulated all over the wound too. Classic dressing was used (Natural Nanoskin ${ }^{\circledR}$ ACT) with antiseptic agents in 06/04/2020 [17]-[22].
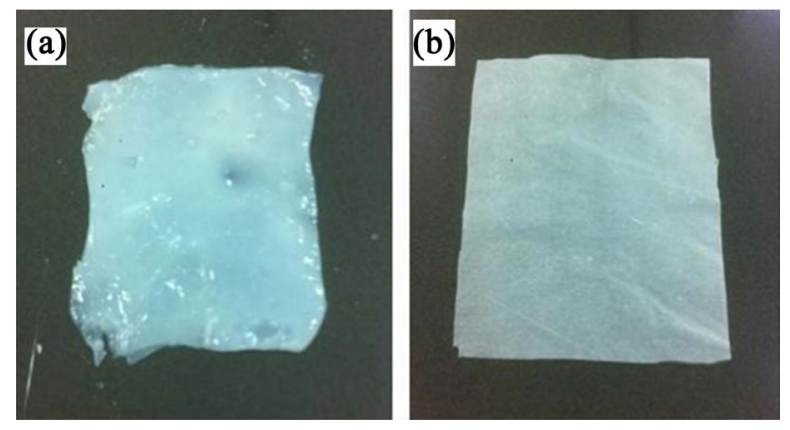

Figure 1. (a) Bacterial cellulose hydrogel and (b) Bacterial cellulose mats [17]-[22]. 
Then, after more 1 month, almost all cancer tissue is removed by treating with Nanoskin ${ }^{\circledR}$-ACT; granulation and building up of new healthy tissue is produced with reduced cancer skin area and the wound is almost close, the same behavior of our article published in 2020 [20] (Figure 3).

In August 2020 (2 months), after using the Bacterial cellulose material in alternated days, it can be observed an excellent new tissue in skin cancer area of the wound and reduced wound area (Figure 2), like patient treatment in above example (Figure 2).

\section{Conclusions}

Bacterial cellulose was successfully modified by changing the fermentation medium with hyaluronic acid, chondroitin sulfate and beta glucan, which produced suitable Natural Nanoskin ${ }^{\circledR}$ ACT Membranes (Bacterial cellulose) for use in skin cancer area.

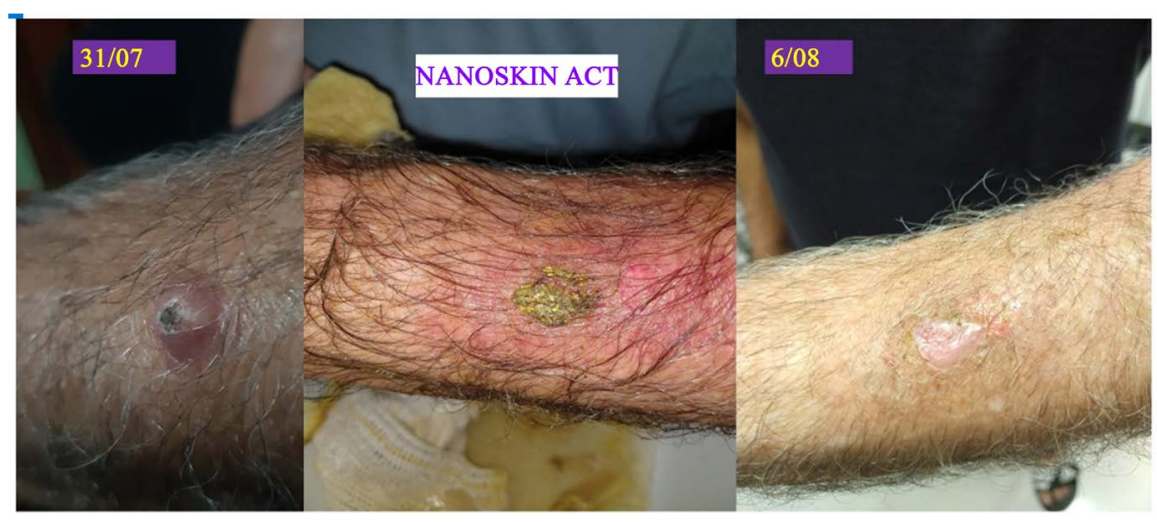

Figure 2. Wound healing in skin cancer treated with Nanoskin ${ }^{\circledR}$-ACT-natural and biological wound dressing (New tissue in 1 treatment week).

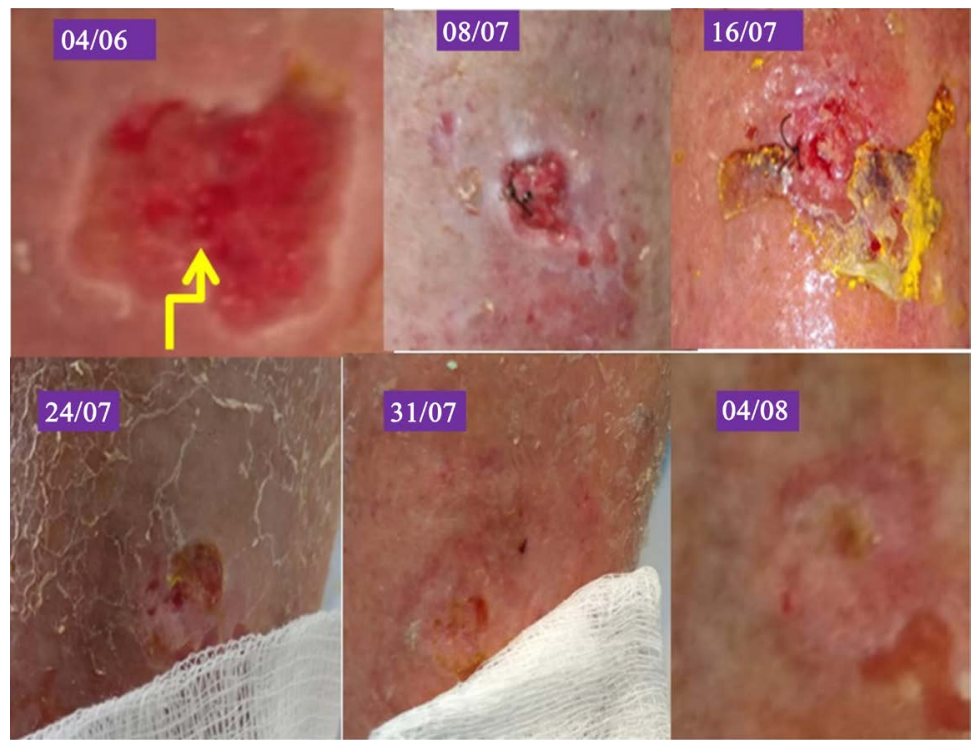

Figure 3. Wound healing evolution in 2 months in patient with skin cancer and Nanoskin $^{\circledR}$-ACT impact use with biological wound dressing. 
Our recent results in skin cancer, is a new and natural treatment for skin cancer wound healing, without cancer drugs, chemotherapy or radiotherapy.

In conclusion, Nanoskin ${ }^{\circledR}$-ACT (Bacterial cellulose membranes) applies for different wound healing treatments, such as in diabetic ulcers, venous ulcers, skin cancer, amputation and different accidents.

\section{Conflicts of Interest}

The authors declare no conflicts of interest regarding the publication of this paper.

\section{References}

[1] Guangtao, C., et al. (2011) Enhancement of the Fraction of the Active Form of an Antitumor Drug Topotecan via an Injectable Hydrogel. Journal of Controlled Release, 156, 21-27. https://doi.org/10.1016/j.jconrel.2011.07.008

[2] Shuming, N., et al. (2007) Nanotechnology Applications in Cancer. Annual Review of Biomedical Engineering, 9, 257-288.

https://doi.org/10.1146/annurev.bioeng.9.060906.152025

[3] Takemi, T., et al. (2009) Nanotechnology for Breast Cancer Therapy. Biomedical Microdevices, 11, 49-63. https://doi.org/10.1007/s10544-008-9209-0

[4] Mansoor, M.A. (2006) Nanotechnology for Cancer Therapy. Taylor \& Francis Group, Abingdon, 810 p.

[5] Lei, L., et al. (2010) Study of $\mathrm{Pt} / \mathrm{TiO}_{2}$ Nanocomposite for Cancer-Cell Treatment. Journal of Photochemistry and Photobiology B: Biology, 98, 207-210. https://doi.org/10.1016/j.jphotobiol.2010.01.005

[6] Warren, N.J., et al. (2014) RAFT Aqueous Dispersion Polymerization Yields Poly(ethylene glycol)-Based Diblock Copolymer Nano-Objects with Predictable Single Phase Morphologies. Journal of the American Chemical Society, 136, 1023-1033. https://doi.org/10.1021/ja410593n

[7] Fraley, S.I., et al. (2012) Dimensional and Temporal Controls of Three-Dimensional Cell Migration by Zyxin and Binding Partners. Nature Communication, 3, 719-732. https://doi.org/10.1038/ncomms1711

[8] Gal, N., et al. (2015) Effects of Particle Uptake, Encapsulation, and Localization in Cancer Cells on Intracellular Applications. Medical Engineering and Physics, 37, 478-483. https://doi.org/10.1016/j.medengphy.2015.03.003

[9] Carrell, R.W. (2005) Cell Toxicity and Conformational Disease. Trends in Cell Biology, 15, 574-580. https://doi.org/10.1016/j.tcb.2005.09.005

[10] Olyveira, G.M., Costa, L.M.M., Riccardi, C.S., Santos, M.L., Daltro, P.B., Basmaji, P., Daltro, G.C. and Guastaldi, A.C. (2016) Bacterial Cellulose for Advanced Medical Materials. In: Grumezescu, A.M., Ed., Nanobiomaterials in Soft Tissue Engineering, Elsevier, Romania, 57-82. https://doi.org/10.1016/B978-0-323-42865-1.00003-9

[11] Olyveira, G.M., Santos, M.L., Costa, L.M.M., Daltro, P.B., Basmaji, P., Daltro, G.C. and Guastaldi, A.C. (2014) Bacterial Biocomposites for Guided Tissue Regeneration.

Science of Advanced Materials, 6, 2673-2678.

https://doi.org/10.1166/sam.2014.1985

[12] Olyveira, G.M., Santos, M.L., Costa, L.M.M., Daltro, P.B., Basmaji, P., Daltro, G.C. and Guastaldi, A.C. (2015) Physically Modified Bacterial Cellulose Biocomposites for Guided Tissue Regeneration. Science of Advanced Materials, 7, 1657-1664. 
https://doi.org/10.1166/sam.2015.2283

[13] Olyveira, G.M., Basmaji, P., Costa, L.M.M., Santos, M.L., Riccardi, C.S., Guastaldi, F.P.S., Scarel-Caminaga, R.M., Oliveira Capote, T.S., Pizoni, E. and Guastaldi, A.C. (2017) Surface Physical Chemistry Properties in Coated Bacterial Cellulose Membranes with Calcium Phosphate. Materials Science \& Engineering. C, Materials for Biological Applications, 75, 1359-1365. https://doi.org/10.1016/j.msec.2017.03.025

[14] Portela, R., Leal, C.R., Almeida, P.L. and Sobral, R.G. (2019) Bacterial Cellulose: A Versatile Biopolymer for Wound Dressing Applications. Microbial Biotechnology, 12, 586-610. https://doi.org/10.1111/1751-7915.13392

[15] Anton-Sales, I., Beekmann, U., Laromaine, A., Roig, A. and Kralisch, D. (2019) Opportunities of Bacterial Cellulose to Treat Epithelial Tissues. Current Drug Targets, 20, 808. https://doi.org/10.2174/1389450120666181129092144

[16] Solway, D.R., Consalter, M. and Levinson, D.J. (2010) Microbial Cellulose Wound Dressing in the Treatment of Skin Tears in the Frail Elderly. Wounds. A Compendium of Clinical Research and Practice, 22, 17-19.

[17] Kaminagakura, K.L.N., Sue Sato, S., Sugino, P., Kataki de Oliveira Veloso, L., Dos Santos, D.C., Padovani, C.R., Basmaji, P., Olyveira, G. and Schellini, S.A. (2019) Nanoskin ${ }^{\circledR}$ to Treat Full Thickness Skin Wounds. Journal of Biomedical Materials Research Part B: Applied Biomaterials, 107, 724-732. https://doi.org/10.1002/jbm.b.34166

[18] Al Mualla, S., Al Nabooda, M., Salman, N., Basmaji, P., De Olyveira, G., Manzine Costa, L., Da Costa Oliveira, J. and Francozo, G. (2018) Special Nanoskin-ACT Biological Membranes from Deep Wounds. Journal of Biomaterials and Nanobiotechnology, 9, 79-88. https://doi.org/10.4236/jbnb.2018.91007

[19] Kanjou, M.M., Abdulhakim, H., Olyveira, G. and Basmaji, P. (2019) 3-D Print Celulose Nanoskin: Future Diabetic Wound Healing. Journal of Biomaterials and Nanobiotechnology, 10, 190-195. https://doi.org/10.4236/jbnb.2019.104011

[20] Basmaji, P. (2020) First Breast Cancer Treatment Naturally by Nanoskin Act. Journal of Biomaterials and Nanobiotechnology, 11, 179-187. https://doi.org/10.4236/jbnb.2020.113011

[21] El-Hoseny, S., Basmaji, P., Olyveira, G., Costa, L., Alwahedi, A., Oliveira, J. and Francozo, G. (2015) Natural ECM-Bacterial Cellulose Wound Healing-Dubai Study. Journal of Biomaterials and Nanobiotechnology, 6, 237-246. https://doi.org/10.4236/jbnb.2015.64022

[22] Mualla, S., Farahat, R., Basmaji, P., Olyveira, G., Costa, L., Oliveira, J. and Francozo, G. (2016) Study of Nanoskin ECM-Bacterial Cellulose Wound Healing/United Arab Emirates. Journal of Biomaterials and Nanobiotechnology, 7, 109-117.

https://doi.org/10.4236/jbnb.2016.72012 